\title{
Internacionalização da Ciência Brasileira: subsídios para avaliação do programa Ciência sem Fronteiras
}

\section{Internationalization of Brazilian Science: contributions to the evaluation of Brazil Science without Borders program}

Guilherme de Rosso Manços

Escola de Artes, Ciências e Humanidades da Universidade de São Paulo (EACH/USP), São Paulo, SP E-mail: guilhermerosso.m@gmail.com

Fernando de Souza Coelho

Escola de Artes, Ciências e Humanidades da Universidade de São Paulo (EACH/USP), São Paulo, SP E-mail: fernandocoelho@usp.br

Resumo: O programa Ciência sem Fronteiras (CsF) concedeu, entre 2011-2016, bolsas a 106 mil estudantes e pesquisadores brasileiros para realizarem intercâmbio acadêmico em 47 países e buscou atrair pesquisadores do exterior para se fixarem no Brasil ou para estabelecerem parcerias com os pesquisadores brasileiros nas áreas prioritárias definidas pelo programa. Neste contexto, este artigo objetiva oferecer alguns subsídios para a avaliação do CsF, especialmente a partir de um compêndio sobre o histórico, justificativa e resultados de implementação do programa; um levantamento e análise de dados que mostram evidências de correlação positiva entre os investimentos em bolsas de mobilidade acadêmica internacional e os níveis de colaboração científica internacional; bem como questionamentos e sugestões para novas pesquisas em torno do tema de colaboração científica internacional. Foram encontrados indícios de que o programa foi capaz de estimular a colaboração internacional entre pesquisadores. Ressalta-se também o entendimento de que o CsF foi positivo no sentido de aumentar a visibilidade internacional da educação superior brasileira e inseriu as universidades e outras instituições brasileiras em programas de cooperação internacional no âmbito da pesquisa. Neste sentido, recomenda-se que o Brasil deve envidar esforços para manter uma política pública de internacionalização e mobilidade acadêmica internacional, aperfeiçoando - naturalmente - o CsF com base na avaliação do programa.

Palavras-chave: Ciência sem Fronteiras; avaliação; internacionalização; cooperação científica

Abstract: The Brazil Science without Borders program (SwB) granted, in five years, academic exchange scholarships to 106 thousand Brazilian students and researches in 47 countries and sought to attract foreign researchers to settle in Brazil or to establish partnerships with Brazilian researchers in priority areas defined by the program. In this context, this paper aims to provide relevant data and information for the SwB evaluation, especially through a compendium about track 
MANÇOS, Guilherme de Rosso e COELHO, Fernando de Souza. Internacionalização da Ciência Brasileira: subsídios para avaliação do programa Ciência sem Fronteiras

history, justification and implementation results of the program; data collection and analysis that show evidence of positive correlations between international academic mobility investments and international scientific collaboration levels; as well as questions and suggestions for further research around the topic of international scientific cooperation. There were indications that the program was able to stimulate and maintain international collaboration among researchers. It is also important to note that SwB was beneficial in order to increase the international visibility of Brazilian higher education and has inserted universities and other Brazilian institutions into international cooperation programs in the field of research. In this sense, it is recommended that Brazil should make efforts to maintain a public policy of internationalization and international academic mobility, improving the SwB based on the program evaluation.

Key-words: Science without Borders, evaluation; internationalization; scientific cooperation

\section{Introdução}

Este artigo tem como intuito colaborar com os esforços de avaliação do programa Ciência sem Fronteiras (CsF), considerando a importância que as políticas públicas de Ciência, Tecnologia e Inovação (CT\&I) e internacionalização têm para um país emergente como o Brasil. Criado em 2011 pelo governo federal, o programa atingiu a meta de conceder bolsas a mais de 101 mil estudantes e pesquisadores brasileiros para realizarem intercâmbio acadêmico em diversas instituições de ensino superior do mundo, de forma que alunos de graduação e pós-graduação estabeleceram contato com sistemas educacionais competitivos em relação à tecnologia e inovação através de experiências de pesquisa e estágio no exterior. Além disso, o CsF buscou atrair pesquisadores do exterior para se fixarem no Brasil ou para estabelecerem parcerias com os pesquisadores brasileiros nas áreas prioritárias definidas pelo programa.

Dada a implementação recente do Ciência sem Fronteiras, as pesquisas de monitoramento e avaliação também são recentes. É possível identificar alguns trabalhos já publicados, sejam dissertações, artigos ou relatórios, sobre determinadas perspectivas de interesse como: gestão do programa (Castro et al., 2012; Aveiro, 2014; Brasil, 2015; E. Oliveira, 2015; Rede CsF, 2015); internacionalização e relações internacionais (Lucches \&; Malanga, 2014; Thiengo \& Mari, 2014; J. Oliveira, 2015; Bido, 2015; Guimarães-Iosif, 2016; Dutra \& Azevedo, 2016; Mcmanus \& Nobre, 2017); línguas estrangeiras e o programa Idiomas sem Fronteiras (IsF) (Soares, 2014;

Revista Brasileira de Políticas Públicas e Internacionais, v.2, n.2, Dezembro/2017, pp. 52-82. 
MANÇOS, Guilherme de Rosso e COELHO, Fernando de Souza. Internacionalização da Ciência Brasileira: subsídios para avaliação do programa Ciência sem Fronteiras

Dorigon, 2015; Martins; Reis, 2015; Archanjo, 2015, 2016; Borges; Garcia-Filice, 2016); bem como formação e currículo (Santos, 2014; Chaves, 2015; Grieco, 2015; Conceição \& França, 2016; L. Oliveira, 2016). O debate também se faz em eventos, simpósios e congressos organizados pelas universidades, pelo governo, pelos parceiros do programa e pela Rede CsF, a associação de bolsistas e ex-bolsistas do Ciência sem Fronteiras. Em complemento, há diversos relatos de experiências individuais e cobertura da mídia acerca do programa, especialmente sobre críticas a sua gestão e implementação, e elogios às histórias de bolsistas que se destacaram no exterior ou após o seu retorno para o Brasil.

Todavia, ainda se explorou muito pouco a perspectiva do resultado do Ciência sem Fronteiras em produção de conhecimento e colaboração científica internacional (Almeida, 2017). Neste momento, se faz necessário aperfeiçoar metodologias existentes e também propor novas abordagens de avaliação nessa dimensão. O Centro de Gestão e Estudos Estratégicos (CGEE) elaborou, em 2013, uma proposta metodológica de avaliação do Ciência sem Fronteiras em quatro dimensões, sendo uma delas a dimensão de produção de conhecimento e internacionalização da ciência brasileira. Tal proposta recomenda a análise da influência do programa Ciência sem Fronteiras nas redes de coautorias internacionais entre países a partir de metodologias bibliométricas. A tentativa de executar a proposta de avaliação sugerida pelo CGEE não obteve êxito devido à dificuldade com a coleta de dados bibliométricos referentes às publicações por áreas prioritárias, pois não há um padrão consolidado de palavras-chave que caracterize tais áreas. A recenticidade da implementação do programa também foi (e ainda é) um fator limitante, uma vez que muitas investigações e suas descobertas científicas podem, respectivamente, demorar vários anos para serem conduzidas a bom termo e publicadas.

Deste modo, o intento deste trabalho é jogar luz em alguns aspectos que podem subsidiar a avaliação do programa Ciência sem Fronteiras. Em linhas gerais, o artigo, após um compêndio sobre o histórico, a justificativa e o processo de implementação do programa, traz um levantamento e análise de dados que mostram indícios de uma influência positiva dos investimentos em bolsas de mobilidade acadêmica internacional em colaboração científica internacional, uma dimensão central para o processo avaliativo do CsF frente às grandes cifras de investimento público dedicadas ao

Revista Brasileira de Políticas Públicas e Internacionais, v.2, n.2, Dezembro/2017, pp. 52-82. 
MANÇOS, Guilherme de Rosso e COELHO, Fernando de Souza. Internacionalização da Ciência Brasileira: subsídios para avaliação do programa Ciência sem Fronteiras

programa (cerca de $\mathrm{R} \$ 13,2$ bilhões entre 2011e 2016) e à opinião pública que divide-se entre apoiadores e críticos, além do recém-anúncio de extinção do CsF pelo governo federal - em abril do ano corrente - na modalidade de cursos de graduação. ${ }^{1}$

O artigo, ao contrário de um manuscrito tradicional de policy studies que, baseado em um referencial teórico, objetiva interpretar ou explicar uma política pública, posta-se mais como um trabalho de policy orientation (Secchi, 2016), buscando sistematizar dados sobre o CsF para dar subsídios informativos e prescritivos ao processo de avaliação desta política pública. Ou seja, aproxima-se de um artigo tecnológico que, no campo das políticas públicas, tem um formato híbrido que justapõe elementos de um policy brief e de uma nota técnica e que pode complementar e/ou contrapor os argumentos dos whitepapers ou relatórios oficiais do governo federal, contribuindo para um processo mais amplo e independente de avaliação formativa do programa - baseado em argumentos contrafactuais e na comparação de evidências.

No que diz respeito ao método deste artigo, empregou-se a triangulação entre a revisão da literatura acadêmica sobre a internacionalização da ciência e o programa Ciências Sem Fronteiras, a análise de documentos oficiais do CsF e o cruzamento de dados de plataformas governamentais e internacionais sobre CT\&I.

\section{Internacionalização e mobilidade acadêmica internacional no Brasil}

As políticas de CT\&I fazem parte das estratégias de crescimento e competitividade dos países. No Brasil, a Estratégia Nacional de Ciência, Tecnologia e Inovação (ENCTI) 2012-2015 identifica cinco desafios para o país e define quatro eixos de sustentação. Dois desses eixos de sustentação indicam anseios por fortalecimento da pesquisa nacional e pela formação e capacitação de recursos humanos para Ciência, Tecnologia e Inovação. E dois desafios explicitam diretamente o interesse em reduzir a defasagem científica e tecnológica entre Brasil e demais países, bem como o interesse pela inserção internacional (Tabela 1).

\footnotetext{
${ }^{1}$ Anúncio divulgado pelo Ministério da Educação (MEC), por meio de nota, em 02 de abril de 2017. Disponível em: <http://portal.mec.gov.br/busca-geral/212-noticias/educacao-superior-1690610854/46981-mec-afirma-que-o-cienciasem-fronteiras-tera-5-mil-bolsistas-na-pos-graduacao $>$.
}

Revista Brasileira de Políticas Públicas e Internacionais, v.2, n.2, Dezembro/2017, pp. 52-82. 
MANÇOS, Guilherme de Rosso e COELHO, Fernando de Souza. Internacionalização da Ciência Brasileira: subsídios para avaliação do programa Ciência sem Fronteiras

Tabela 1 - Desafios e eixos de sustentação da ENCTI 2012-2015

\begin{tabular}{c|l}
\hline \hline \multirow{2}{*}{ Desafios } & $\begin{array}{l}\text { Redução da defasagem científica e tecnológica que ainda separa o Brasil das nações } \\
\text { mais desenvolvidas. }\end{array}$ \\
\cline { 2 - 2 } Eustentação da & Consolidação do novo padrão de inserção internacional do Brasil. \\
\cline { 2 - 2 } ENCTI & Fortalecimento da pesquisa e da infraestrutura científica e tecnológica. \\
\hline \hline
\end{tabular}

Fonte: Elaborado pelos autores com base nas informações da ENCTI 2012-2015.

Globalização e internacionalização relacionam-se entre si, porém, segundo Altbach e Knight (2007), não são a mesma coisa. Para os autores, a globalização é o contexto de tendências econômicas e acadêmicas que são parte da realidade do século XXI. E internacionalização inclui as políticas e práticas executadas por sistemas acadêmicos e instituições - e até mesmo indivíduos para lidar com o ambiente acadêmico global. Internacionalização também pode ser entendido como o processo de integrar uma dimensão internacional e cultural no funcionamento de ensino, pesquisa e extensão do ensino superior (Knight, 1994). Dessa maneira, corroborado por diferentes autores, a internacionalização não é um objetivo em si, mas sim um processo para auxiliar as Instituições de Ensino Superior (IES) a melhorarem a qualidade do seu ensino, pesquisa e extensão ao integrarem uma dimensão internacional/intercultural em seu funcionamento (Jibeen \& Khan, 2015; Wit, 1998). Considerando os fatores de importância da internacionalização, é possível articular os diferentes atores para realizarem ações conjuntas em prol de benefícios comuns. E parte dessas ações são os programas de mobilidade acadêmica internacional.

Revista Brasileira de Políticas Públicas e Internacionais, v.2, n.2, Dezembro/2017, pp. 52-82. 
MANÇOS, Guilherme de Rosso e COELHO, Fernando de Souza. Internacionalização da Ciência Brasileira: subsídios para avaliação do programa Ciência sem Fronteiras

A mobilidade acadêmica internacional de estudantes, professores e pesquisadores é uma forma de realizar estudos, treinamentos e pesquisas em instituições de outros países. Diversas nações desenvolvem programas de cooperação internacional visando a mobilidade acadêmica, sendo esta uma das atividades que mais se destacam no processo de internacionalização. É possível citar exemplos como: (i) 100K US-China Strong (Estados Unidos); (ii) Erasmus Mundus (União Europeia); (iii) University Mobility in Asia and the Pacific (UMAP); dentre outros.

Ao analisar o contexto brasileiro, a evolução do número de bolsas no exterior implementadas pelas agências governamentais CAPES e CNPq segue uma tendência de crescimento lento até o ano de 2011, salvo um período de maior intensidade entre as décadas de 1980 e 1990 que se reduz em seguida. A partir de 2012, ano de implementação do Ciência sem Fronteiras, é possível observar um aumento significativo na implementação de bolsas no exterior por ambas as agências, como demonstram as Figuras 1 e 2. No biênio 2014-2015, a agência do MEC foi bastante expressiva e concedeu 84.737 bolsas no exterior, cerca de quatro vezes mais do que a agência do MCTI, que por sua vez implementou 20.027 no mesmo período.

Figura 1 - Número de bolsas no exterior implementadas pelo CNPq no período 1952-2015

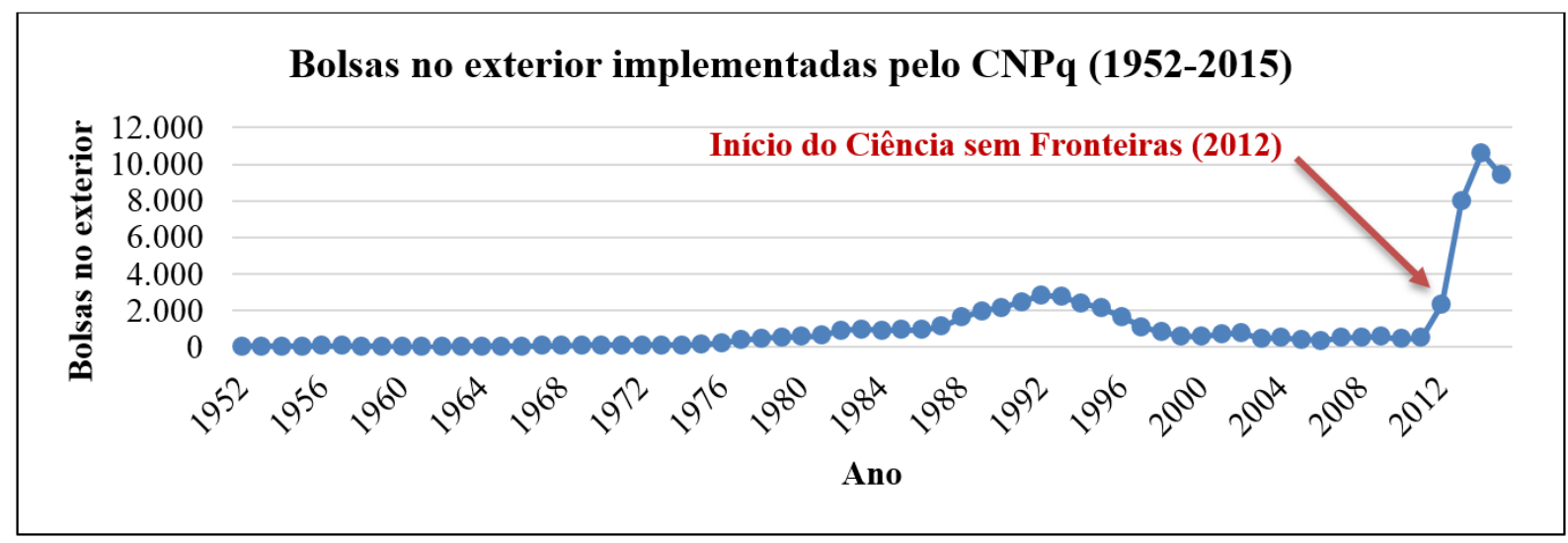

Fonte: Elaborado pelos autores com dados das séries históricas do CNPq.

Revista Brasileira de Políticas Públicas e Internacionais, v.2, n.2, Dezembro/2017, pp. 52-82. 
MANÇOS, Guilherme de Rosso e COELHO, Fernando de Souza. Internacionalização da Ciência Brasileira: subsídios para avaliação do programa Ciência sem Fronteiras

Figura 2 - Número de bolsas no exterior implementadas pela CAPES no período 1998-2015

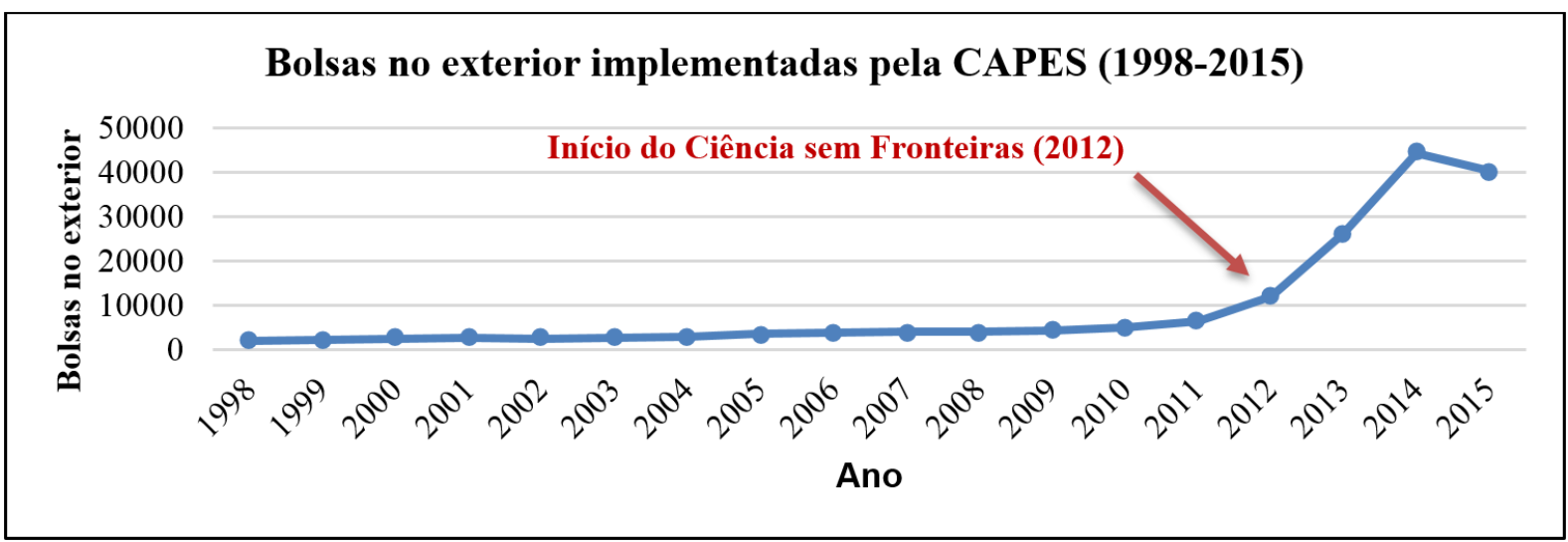

Fonte: Elaborado pelos autores com dados da plataforma GEOCAPES.

A iniciativa conjunta de intercâmbios educacionais em ciências se tornou uma ferramenta da moderna diplomacia estratégica. Relatos diplomáticos indicam que diante das iniciativas do presidente norte americano Barack Obama de enviar 100.000 estudantes americanos para a China entre 2010 e 2014, e 100.000 para a América Latina - programa 100K Strong for America - até 2020, a então presidente brasileira Dilma Rousseff ficou "impressionada com a abrangência e a ambição da iniciativa americana” (SIC) e, neste sentido, comprometeu-se a equiparar as ações ainda em 2011 (Shannon, 2012), sendo esta uma das possíveis inspirações (e motivações) para criar um expressivo programa de mobilidade acadêmica internacional como o Ciência sem Fronteiras, caracterizado na seção 2.

\section{Caracterização do programa Ciência sem Fronteiras}

O programa Ciência sem Fronteiras foi instituído pelo Decreto $n^{0} 7.642$ (2011), com o objetivo de "propiciar a formação e capacitação de pessoas com elevada qualificação (...), além de atrair para o Brasil jovens talentos e pesquisadores estrangeiros de elevada qualificação”. A meta global de bolsas foi estipulada em 101.000, sendo a expectativa inicial de financiamento de 75.000

Revista Brasileira de Políticas Públicas e Internacionais, v.2, n.2, Dezembro/2017, pp. 52-82. 
MANÇOS, Guilherme de Rosso e COELHO, Fernando de Souza. Internacionalização da Ciência Brasileira: subsídios para avaliação do programa Ciência sem Fronteiras

bolsas com recursos do Governo Federal e de 26.000 bolsas com recursos provenientes da iniciativa privada. De acordo com a ferramenta Bolsistas Pelo Mundo, o programa enviou bolsistas para instituições de ensino e pesquisa em quarenta e sete diferentes países do globo (incluindo Brasil) até 2016. A Figura 3 mostra os 30 países que mais receberam bolsistas do CsF, indicando que os Estados Unidos receberam 27.821 bolsistas, o Reino Unido 10.740, o Canadá 2.321, a França 7.279, e países como Suíça, Áustria, Chile, México, África do Sul, entre outros receberam menos de 200 bolsistas.

Figura 3 - Distribuição total de bolsas do CsF implementadas por país de destino (30+)

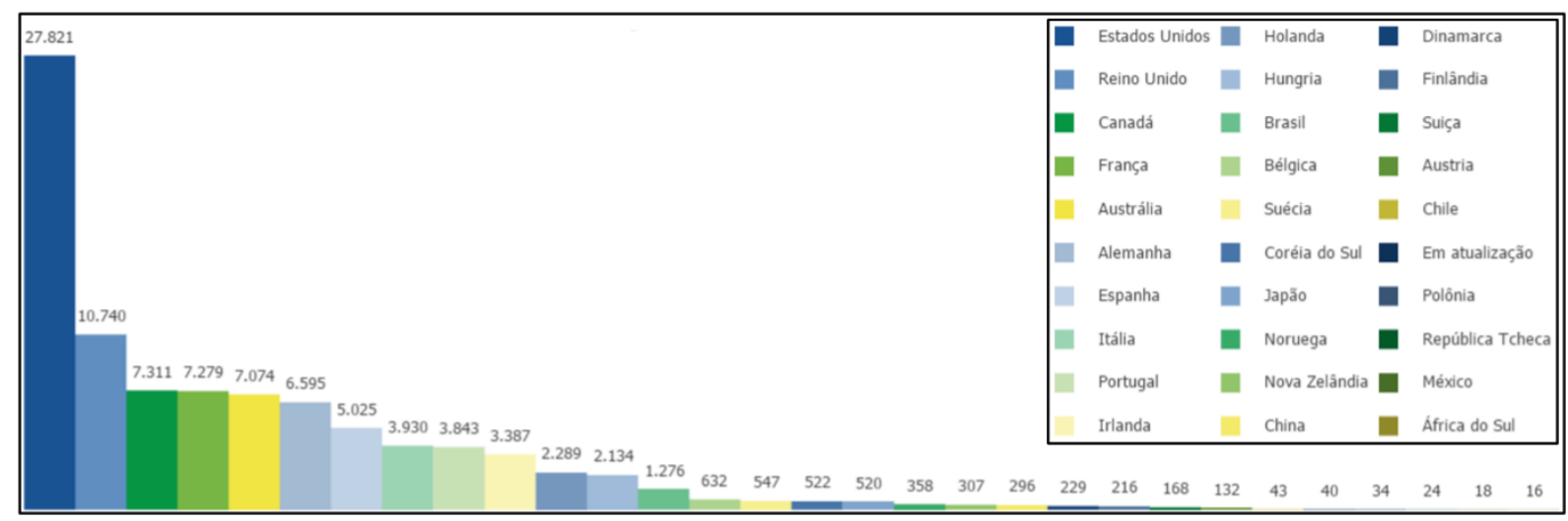

Fonte: Painel de Controle do Programa Ciência sem Fronteiras (Brasil, 2016).

Há sete tipos de modalidades de bolsa, sendo cinco para mobilidade OUT, ou seja, para estudantes e pesquisadores brasileiros realizarem intercâmbio acadêmico no exterior, e duas modalidades para mobilidade IN, ou seja, para pesquisadores estrangeiros e brasileiros radicados no exterior realizarem intercâmbio acadêmico no Brasil. Do total de bolsas concedidas, aproximadamente 92\% foram implementadas até janeiro de 2016, como demonstra a Tabela 2. As bolsas implementadas são aquelas em que já houve alguma transferência de recursos ao bolsista e, portanto, explicita-se que o número de concessões antecede o de implementações. Graduação sanduíche no exterior foi a modalidade que mais recebeu bolsas, representando 78,98\% do total de Revista Brasileira de Políticas Públicas e Internacionais, v.2, n.2, Dezembro/2017, pp. 52-82. 
MANÇOS, Guilherme de Rosso e COELHO, Fernando de Souza. Internacionalização da Ciência Brasileira: subsídios para avaliação do programa Ciência sem Fronteiras

bolsas implementadas. A pós-graduação e pós-doutorado no exterior receberam 19,65\% das bolsas do Ciência sem Fronteiras e pesquisadores em mobilidade IN representam 1,38\% das bolsas implementadas.

Tabela 2 - Panorama geral da implementação de bolsas do CsF de 2012 até janeiro de 2016

\begin{tabular}{|c|c|c|c|}
\hline Modalidade de Bolsa & $\begin{array}{c}\text { Meta do } \mathrm{n}^{\circ} \text { de } \\
\text { bolsas }\end{array}$ & $\begin{array}{c}\text { Bolsas } \\
\text { implementadas }\end{array}$ & $\begin{array}{c}\text { \% } \text { atingida da } \\
\text { meta }\end{array}$ \\
\hline "Graduação Sanduíche no Exterior & 64.000 & 73.353 & $114,61 \%$ \\
\hline Mestrado no Exterior & --- & 558 & --- \\
\hline Doutorado Sanduíche no Exterior & 15.000 & 9.685 & $65,77 \%$ \\
\hline Doutorado Pleno no Exterior & 4.500 & 3.353 & $74,51 \%$ \\
\hline Pós-doutorado no Exterior & 6.440 & 4.652 & $72,24 \%$ \\
\hline $\begin{array}{l}\text { Atração de Jovens Talentos } \\
\text { (no Brasil) }\end{array}$ & 2.000 & 504 & $25,20 \%$ \\
\hline $\begin{array}{l}\text { Pesquisador Visitante Especial } \\
\text { (no Brasil) }\end{array}$ & 2.000 & 775 & $38,75 \%$ \\
\hline $\begin{array}{l}\text { Desenvolvimento Tecnológico e Inovação } \\
\text { no Exterior }\end{array}$ & 7.060 & --- & --- \\
\hline Total & 101.000 & 92.880 & $91,96 \%$ \\
\hline
\end{tabular}

Fonte: Elaborado pelos autores com base nos dados o Painel de Controle do Programa Ciência sem Fronteiras (Brasil, 2016).

Revista Brasileira de Políticas Públicas e Internacionais, v.2, n.2, Dezembro/2017, pp. 52-82. 
MANÇOS, Guilherme de Rosso e COELHO, Fernando de Souza. Internacionalização da Ciência Brasileira: subsídios para avaliação do programa Ciência sem Fronteiras

O programa define dezoito áreas prioritárias contempladas, sendo a área de 'engenharia e demais áreas tecnológicas' a que mais distribuiu bolsas, 41.594 no total, seguido por 'biologia, ciências biomédicas e da saúde’ com 16.076 e 'indústria criativa’ com 8.061. Até a última atualização dos dados em janeiro de 2016, a área prioritária de ‘tecnologia mineral’ foi a área menos contemplada, com 136 bolsas distribuídas no total (Figura 4).

Figura 4 - Distribuição total de bolsas do CsF implementadas por área prioritária

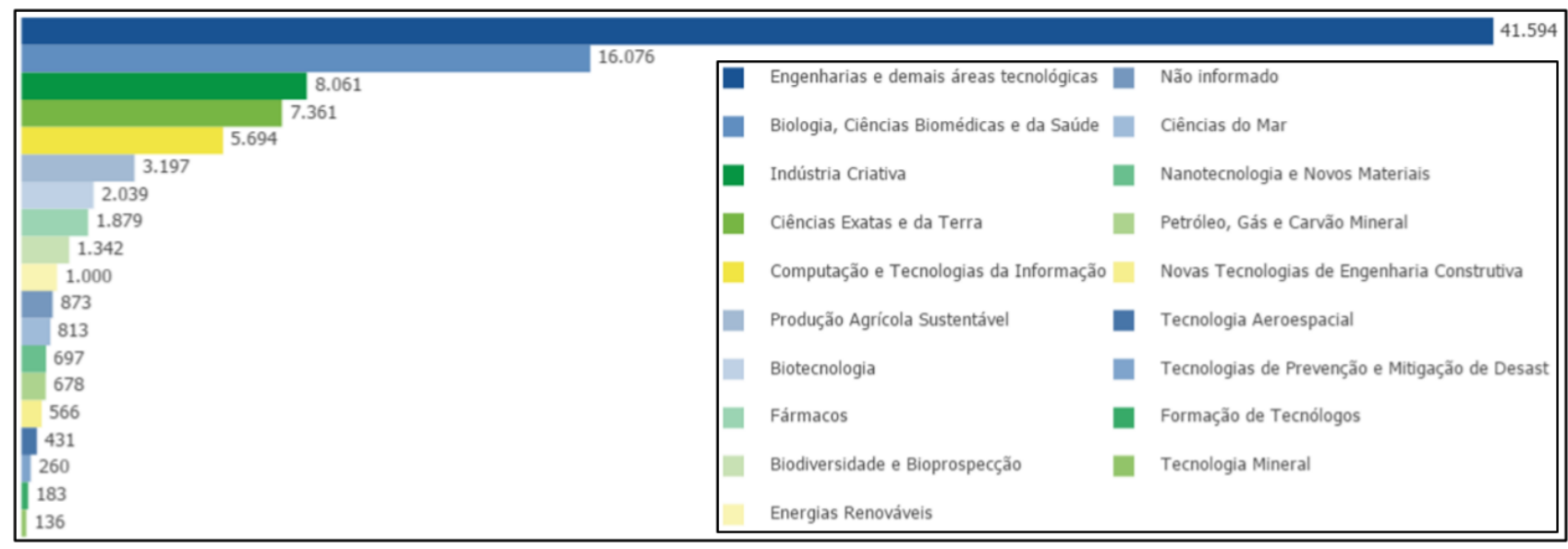

Fonte: Painel de Controle do Programa Ciência sem Fronteiras (Brasil, 2016).

Na análise das bolsas implementadas por instituição de origem, a Universidade de São Paulo (USP) foi a instituição de ensino superior brasileira que mais teve bolsistas do Ciência sem Fronteiras, 5.541 no total. Destas, 72,75\% foram destinadas para a graduação, 24,91\% para pósgraduação e pós-doutorado, e as demais para mobilidade IN.

Tais dados podem levar ao debate sobre estratégias de priorização de bolsas para graduação, pós-graduação ou ambos. Observam-se questionamentos de alguns especialistas em C\&T se a maior parte do investimento em mobilidade acadêmica internacional deveria ser para estudantes de graduação, enquanto o foco de desenvolvimento científico acontece mais na pós-

Revista Brasileira de Políticas Públicas e Internacionais, v.2, n.2, Dezembro/2017, pp. 52-82. 
MANÇOS, Guilherme de Rosso e COELHO, Fernando de Souza. Internacionalização da Ciência Brasileira: subsídios para avaliação do programa Ciência sem Fronteiras

graduação. Há, contudo, pesquisadores que acreditam ter sido importante levar muitos alunos de graduação para o exterior, haja vista que eles ainda não possuem “raízes” científicas com grupos de pesquisa no Brasil e podem ir mais abertos a explorar novas áreas de pesquisas não existentes no país de origem. Fato é que muitos questionamentos apenas poderão ser respondidos no médio ou longo prazo, com a avaliação de impacto do programa.

A título de ilustração, alguns dos tópicos de debate ainda sem convergência de opiniões dizem respeito aos critérios de seleção do programa e a priorização por certos cursos em detrimento de outros; ao real investimento privado frente ao aporte que se esperava quando se planejou o programa; às questões de proficiência em idiomas e o impacto na experiência acadêmica; à fuga de cérebros e à fixação dos talentos; aos recursos e fontes orçamentárias para a manutenção do programa; e à própria gestão e avaliação do programa. Enfim, todos esses aspectos do programa CsF são ávidos por avaliações e passíveis de julgamento sob diferentes abordagens, mecanismos lógicos, padrões e indicadores para discutir as qualidades e deficiências desta política pública de CT\&I.

\section{Alguns subsídios para a avaliação do programa Ciência sem Fronteiras}

Esta seção, tal como uma apresentação de resultados e discussões, segue uma ordem sequencial - do ciclo de políticas públicas e está dividida em três subseções. Inicialmente, apresentamos uma contextualização sobre o cenário de formação de recursos humanos e de produção do conhecimento a partir de dados históricos consolidados, buscando identificar a situação do Brasil no cenário internacional e as estratégias adotadas pelo país em CT\&I - ou seja, a identificação do problema, a formação da agenda e a formulação de alternativa do CsF. Na sequência, sistematizamos alguns dados sobre a execução de investimentos em bolsas de formação de recursos humanos por parte das agências CAPES e CNPQ, mostrando as implicações do programa Ciência sem Fronteiras nesses investimentos - isto é, a tomada de decisão e a implementação. Na parte final, discutimos a colaboração científica internacional e exploramos um exemplo de coautoria vinculada à mobilidade acadêmica - apontando subsídios para a avaliação do

Revista Brasileira de Políticas Públicas e Internacionais, v.2, n.2, Dezembro/2017, pp. 52-82. 
MANÇOS, Guilherme de Rosso e COELHO, Fernando de Souza. Internacionalização da Ciência Brasileira: subsídios para avaliação do programa Ciência sem Fronteiras

CsF nessa dimensão.

\subsection{Formação de recursos humanos e produção de conhecimento}

A formação de recursos humanos qualificados em ciências básicas, engenharias e demais áreas tecnológicas é essencial para o funcionamento dos sistemas de ciência, tecnologia e inovação e, consequentemente, para o desenvolvimento de longo prazo dos países. No início da década, em 2010, o Brasil formou 40.921 engenheiros, quantidade equivalente a apenas 4,93\% de todos os 829.286 diplomas entregues aos concluintes do ensino superior naquele ano. Para a área de ‘ciências, matemática e computação’, que contempla 35 cursos de nível superior agrupados em 11 subáreas, o número de concluintes em 2010 foi equivalente 6,29\% do total de diplomados no país (Brasil, 2010).

Quando analisamos a disponibilidade de recursos humanos no país que atuam com pesquisa e desenvolvimento $(\mathrm{P} \& \mathrm{D})$, vemos que o Brasil possui cerca de 700 profissionais em $\mathrm{P} \& \mathrm{D}$ para cada um milhão de habitantes. Isso é pouco se comparado com países desenvolvidos como Estados Unidos, Canadá e Reino Unido, que possuem cerca de 4.000 pesquisadores por milhão de habitantes, ou a Dinamarca e Israel, que possuem, respectivamente, mais de 7.000 e 8.000 pesquisadores por milhão de habitantes no país. O Brasil também investe proporcionalmente menos recursos em $\mathrm{P} \& \mathrm{D}$ do que os países desenvolvidos, cerca de 1,2\% do Produto Interno Bruto (PIB), quando a média da OCDE é 2,4\% e Israel ultrapassa 4,0\% (World Bank, 2016).

A Figura 5 considera os 85 países que investem pelo menos 0,2\% do PIB em P\&D e apresenta uma dispersão entre os valores de investimento em $\mathrm{P} \& \mathrm{D}$ e o número de pesquisadores por milhão de habitantes. A região amarela destaca um claro padrão existente entre os países desenvolvidos (perspectiva social e econômica), que realizam investimentos na ordem 1,5\% ou mais e dispõem 4.000 ou mais pesquisadores por milhão de habitantes.

Revista Brasileira de Políticas Públicas e Internacionais, v.2, n.2, Dezembro/2017, pp. 52-82. 
MANÇOS, Guilherme de Rosso e COELHO, Fernando de Souza. Internacionalização da Ciência Brasileira: subsídios para avaliação do programa Ciência sem Fronteiras

Figura 5 - Dispersão entre investimento em P\&D como porcentagem do Produto Interno Bruto (PIB) e pesquisadores em P\&D por milhão de habitantes

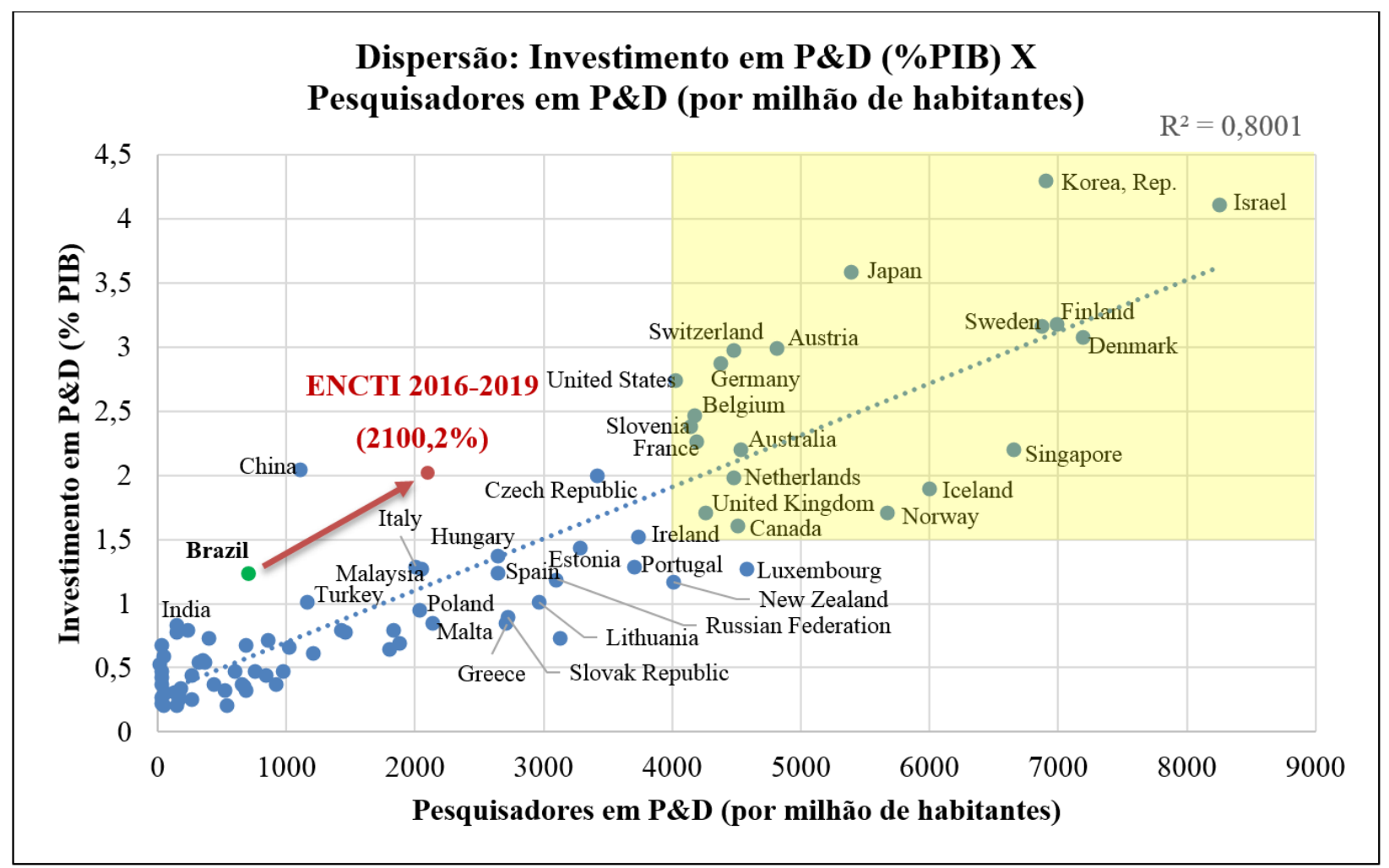

Fonte: Elaborado pelos autores com dados do World Bank, média para os anos de 2004-2015.

No que diz respeito à produção de conhecimento e ao desenvolvimento tecnológico, a posição econômica do Brasil não se reflete nos resultados de produção de conhecimento científico nem de desenvolvimento tecnológico. Em um comparativo de década, o Brasil saiu da $17^{a}$ posição quanto ao número de publicações indexadas pela Scopus em 2001, quando era responsável por 1,16\% da produção científica mundial, para a $13^{\mathrm{a}}$ colocação no ranking em 2010, quando registrou 49.778 publicações científicas e passou a representar 1,85\%. Entretanto, é apenas o $23^{\circ}$ na classificação por Índice H (Scopus, 2016) - índice que quantifica a produtividade e o impacto dos

Revista Brasileira de Políticas Públicas e Internacionais, v.2, n.2, Dezembro/2017, pp. 52-82. 
MANÇOS, Guilherme de Rosso e COELHO, Fernando de Souza. Internacionalização da Ciência Brasileira: subsídios para avaliação do programa Ciência sem Fronteiras

trabalhos a partir do número de citações. Considerando publicações entre 1996-2016, o Índice H do Brasil é 461, ou seja, há 461 publicações científicas com pelo menos 461 citações. Dentre os países do BRICS, estão à frente do Brasil: a China com Índice H 655, a Índia com 478 e a Rússia com 467.

Quando analisados os dados de produção de conhecimento tecnológico, o Brasil demonstra crescimento quanto ao número de pedidos de patentes internacionais registrados no Patent Cooperation Treaty (PCT), saindo de 173 pedidos em 2001 para um pico de 619 pedidos em 2012. Porém, quando comparado a outros países, o Brasil é apenas o $25^{\circ}$ da lista, indicando pouca expressão no cenário internacional com apenas 0,25\% de todos os 218.000 pedidos de patentes internacionais do mundo em 2015. Esta evolução do Brasil no período 2001-2015 é pouco significante frente aos cinco países que mais realizam pedidos de patentes internacionais. Em 2001, os Estados Unidos realizaram 43.060 pedidos de patentes, valor que o Japão, segundo colocado da lista, foi alcançar apenas em 2012. A China foi o país que proporcionalmente mais cresceu, elevando em 1.625\% o número de pedidos de patentes entre 2001 e 2015, frente a 217\% de crescimento brasileiro (World Intellectual Property Organization [WIPO], 2017).

Diante dos dados e informações supracitados, pode-se identificar dois problemas principais acerca do cenário brasileiro em ciência, tecnologia e inovação no início da década de 2010:

1. Déficit de recursos humanos qualificados, especialmente nas áreas de ciências básicas, engenharias e demais áreas tecnológicas;

2. Baixa inserção científica e tecnológica no cenário internacional.

Terziev e Georgiev (2017) afirmam que o fator chave para o desenvolvimento socioeconômico são pessoas e, de forma similar, Bernal (1939) analisa a conexão entre o trabalho feito por cientistas e o desenvolvimento socioeconômico no mundo ao seu redor ao falar da função social da ciência. Como já mencionado nesta seção, há uma correlação entre o nível de desenvolvimento socioeconômico de um país com o investimento em pesquisa e desenvolvimento e com a disponibilidade de pesquisadores e recursos humanos qualificados.

Em termos de internacionalização, a rede de colaboração científica internacional tem sido dominada por algumas nações europeias e pelos Estados Unidos, ao tempo que tal rede está rapidamente se expandindo para um nível global. Esta mudança de relação entre as dimensões

Revista Brasileira de Políticas Públicas e Internacionais, v.2, n.2, Dezembro/2017, pp. 52-82. 
MANÇOS, Guilherme de Rosso e COELHO, Fernando de Souza. Internacionalização da Ciência Brasileira: subsídios para avaliação do programa Ciência sem Fronteiras

geográficas e intelectuais da ciência também influi em implicações nas políticas de CT\&I dos países (Leydesdorff et al., 2013).

O entendimento de tais estudos reforça, portanto, a relevância dos problemas indicados anteriormente para o desenvolvimento socioeconômico do Brasil. Neste sentido, argumenta-se que, dada a caracterização do Brasil no cenário internacional, tanto no cenário de formação de recursos humanos quanto em produção de conhecimento científico e tecnológico, havia em 2011 justificativas plausíveis para a criação de um programa de mobilidade acadêmica internacional. Este argumento é reforçado estrategicamente com a definição das linhas de ação da ENCTI 2012-2015 que visam, igualmente, "ampliar e robustecer a formação de recursos humanos estratégicos, com foco nas ciências básicas e nas engenharias (...) e o consequente aumento da inserção da ciência brasileira nas redes internacionais de P\&D” (Brasil, 2012, grifo nosso).

Também na ECNTI 2012-2015, o Ministério de Ciência, Tecnologia e Inovação delineou os programas prioritários para os setores portadores de futuro. O programa CsF, planejado para ser uma política - inicialmente - com quatro anos de implementação, alinhava-se a essa estratégia de governo ao indicar dezoito áreas contempladas para a destinação de bolsas de mobilidade acadêmica internacional. Após a fase de formação da agenda dentro do ciclo de políticas públicas, surge em 2011 a formulação do Ciência sem Fronteiras, um programa governamental que busca “promover a consolidação, expansão e internacionalização da ciência e tecnologia, da inovação e da competitividade brasileira por meio do intercâmbio e da mobilidade internacional [de recursos humanos]"2.

\subsection{Agências de fomento: bolsas e investimentos}

Todos os bolsistas do Ciência sem Fronteiras no exterior gozaram de auxílios financeiros para deslocamento aéreo, instalação e seguro saúde, além de uma mensalidade cujo os valores são definidos por modalidade. Os valores de mensalidade para bolsas do Ciência sem Fronteiras no país foram definidos de acordo com a Portaria n ${ }^{\circ}$ 60, de 4 de maio de 2015 da CAPES. O custo médio

\footnotetext{
${ }^{2}$ Retirado do site do programa Ciência sem Fronteiras: www.cienciasemfronteiras.gov.br, grifo nosso.

Revista Brasileira de Políticas Públicas e Internacionais, v.2, n.2, Dezembro/2017, pp. 52-82.
} 
MANÇOS, Guilherme de Rosso e COELHO, Fernando de Souza. Internacionalização da Ciência Brasileira: subsídios para avaliação do programa Ciência sem Fronteiras

anual de um bolsista de graduação sanduíche foi de US\$33.752,43 e de doutorado pleno US\$39.946,65. O orçamento inicial previsto era de R\$3,16 bilhões (Gardner, 2011), porém de acordo com dados da CAPES e do CNPq atualizados até o ano de 2015, o investimento total acumulado com o Ciência sem Fronteiras atingiu o montante de R\$10.333.837.324,48, conforme a Figura 6.

Figura 6 - Investimentos do programa CsF (CAPES + CNPq) ano a ano (2011-2015)

\section{Investimentos do Ciência sem Fronteiras (CAPES + CNPq) 2011-2015}

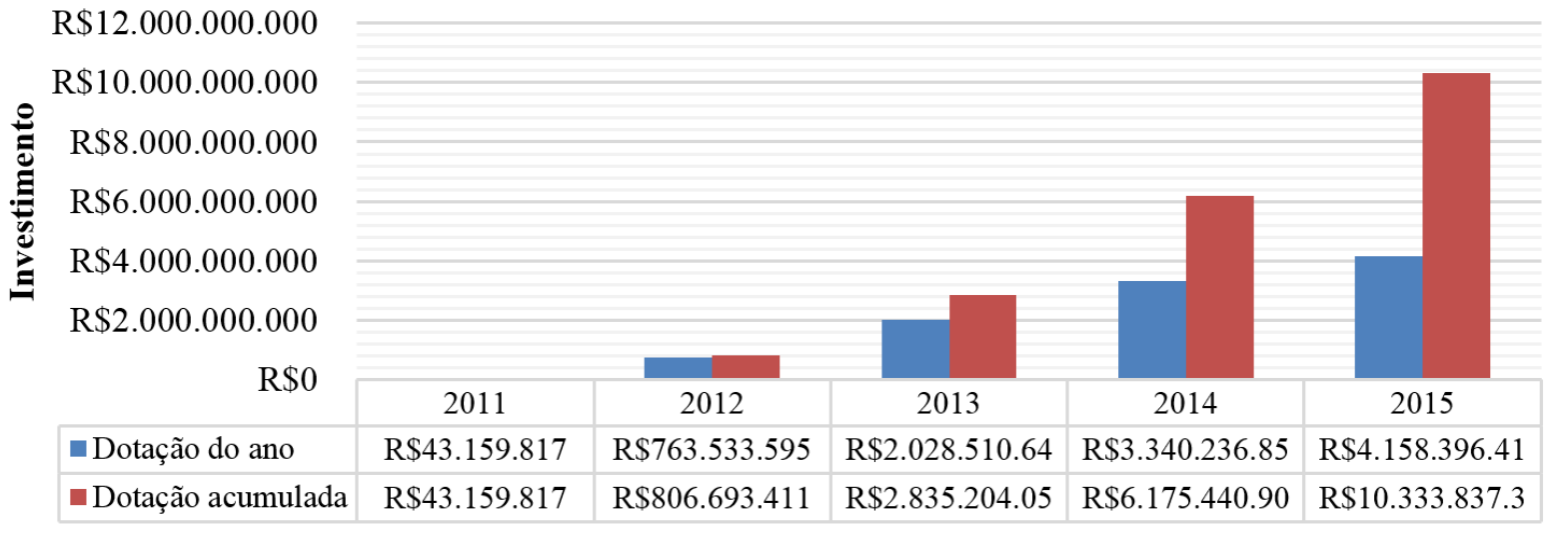

Fonte: Adaptado pelos autores do "Relatório de avaliação do programa Ciência sem Fronteiras”, do Senado Federal, 2015, p. 38, com dados da CAPES e CNPQ.

Ao analisar os dados de bolsas no exterior oferecidas pelo CNPq, sabe-se que parte é destinada para Formação e Qualificação nos níveis de graduação e doutorado, e outra parte para Estímulo à Pesquisa, especialmente para pós-doutorado. As quatro principais modalidades de bolsas no exterior oferecidas pelo CNPq tiveram evolução perceptível com o início do programa Ciência sem Fronteiras em 2012. É importante ressaltar que nesse período de crescimento a maior parte da quantidade total de bolsas do CNPq foi destinada para graduação sanduíche, que não existiam em 2011 e atingiram um pico de 9.155 bolsas em 2014. Para a modalidade de doutorado sanduíche, o Revista Brasileira de Políticas Públicas e Internacionais, v.2, n.2, Dezembro/2017, pp. 52-82. 
MANÇOS, Guilherme de Rosso e COELHO, Fernando de Souza. Internacionalização da Ciência Brasileira: subsídios para avaliação do programa Ciência sem Fronteiras

aumento foi de 222 bolsas em 2011 para 588 em 2015, ou 164,7\% no período comparado. Entre 2011 e 2015, houve um crescimento de 991,22\% na oferta de bolsas de doutorado pleno no exterior, que cresceram de 96 para 1.045 em número absolutos, e o pós-doutorado no exterior cresceu 507,35\% recebendo 994 bolsas em 2015.

O padrão de crescimento do número de bolsas no exterior e do montante de investimento por parte da CAPES é similar ao CNPq. Mas é importante analisar também a estratificação dessas bolsas de acordo com as grandes áreas do conhecimento. A evolução percentual das bolsas para engenharias e ciências exatas e da terra, em relação ao total de bolsas, cresce significativamente a partir de 2012. De forma oposta, há redução percentual na distribuição de bolsas para as grandes áreas de humanas, linguística, letras e artes. Entretanto, a redução percentual do número de bolsas não necessariamente significa que também houve redução do número absoluto.

Na verdade, os dados da CAPES mostram que houve crescimento absoluto na quantidade de bolsas para todas as nove grandes áreas do conhecimento, mesmo com a alta demanda de recursos financeiros alocada para as áreas de ciências básicas e engenharias a partir da implementação do programa Ciência sem Fronteiras. A tabela 3 mostra que em 2015 houve um crescimento de 881,52\% em relação a 2011 para a grande área de engenharia. A grande área de ciência humanas recebeu 5,82\% das bolsas no exterior implementadas pela CAPES em 2015, equivalente a 2.347 em valores absolutos e significando crescimento de 161,36\% em relação às 898 bolsas, ou 14,89\%, em 2011.

Revista Brasileira de Políticas Públicas e Internacionais, v.2, n.2, Dezembro/2017, pp. 52-82. 
MANÇOS, Guilherme de Rosso e COELHO, Fernando de Souza. Internacionalização da Ciência Brasileira: subsídios para avaliação do programa Ciência sem Fronteiras

Tabela 3 - Crescimento de bolsas no exterior implementadas pela CAPES entre os anos 2011 e 2015, por grande área

\begin{tabular}{|c|c|c|c|c|}
\hline \multirow{3}{*}{ Grande Área } & \multicolumn{2}{|c|}{ Ano } & \multirow{3}{*}{ Crescimento absoluto } & \multirow{3}{*}{$\begin{array}{c}\text { Crescimento } \\
\text { em \% }\end{array}$} \\
\hline & & & & \\
\hline & 2011 & 2015 & & \\
\hline Ciências agrárias & 518 & 2.706 & 2.188 & 422,39\% \\
\hline Ciências biológicas & 717 & 2.351 & 1.634 & $227,89 \%$ \\
\hline Ciências da saúde & 489 & 3.484 & 2.995 & $612,47 \%$ \\
\hline Ciências exatas e da terra & 874 & 5.163 & 4.289 & $490,73 \%$ \\
\hline Ciências humanas & 898 & 2.347 & 1.449 & $161,36 \%$ \\
\hline Ciências sociais aplicadas & 468 & 5.001 & 4.533 & $968,59 \%$ \\
\hline Engenharias & 1.650 & 16.195 & 14.545 & $881,52 \%$ \\
\hline Linguística, letras e artes & 557 & 1.355 & 798 & $143,27 \%$ \\
\hline Multidisciplinar & 183 & 1.709 & 1.526 & $833,88 \%$ \\
\hline Total $^{3}$ & 6.031 & 40.324 & 33.963 & $533,93 \%$ \\
\hline
\end{tabular}

Fonte: Elaborado pelos autores com dados da plataforma GEOCAPES.

Observa-se, portanto, que o aumento de investimentos em bolsas no exterior para as áreas contempladas pelo Ciência sem Fronteiras não demandou realocação de recursos no sentido de reduzir o investimento em bolsas no exterior para as áreas não contempladas. Uma das hipóteses é

\footnotetext{
${ }^{3} \mathrm{O}$ número total de bolsas é equivalente ao valor somado de todas as bolsas por grande área mais as bolsas em que a grande área não foi informada.
}

Revista Brasileira de Políticas Públicas e Internacionais, v.2, n.2, Dezembro/2017, pp. 52-82. 
MANÇOS, Guilherme de Rosso e COELHO, Fernando de Souza. Internacionalização da Ciência Brasileira: subsídios para avaliação do programa Ciência sem Fronteiras

que outros programas de mobilidade acadêmica já existentes e que tinham vagas disputadas por todas as grandes áreas, agora estão com menos competição, uma vez que o CsF direcionou as áreas contempladas para um único programa. Outras possíveis influências seriam o fortalecimento dos escritórios de relações internacionais nas universidades, a quantidade de informações sobre intercâmbio produzidas e disponíveis na mídia sobre intercâmbio e o natural aumento do interesse pela mobilidade acadêmica por partes de estudantes e pesquisadores em todas as áreas do conhecimento. Ademais, os dados da CAPES também indicam que o programa não afetou negativamente o número de bolsas de formação no país, que demonstra crescimento contínuo desde 2008. De 2011, quando o total de bolsas implementadas no país foi 70.233, para 2014, quando o total subiu para 90.065, todas as grandes áreas tiveram evolução positiva.

Finalizando esta análise sobre bolsas e investimentos, entende-se que o Ciência sem Fronteiras atingiu a meta de concessão de bolsas no exterior, porém extrapolou em cerca de três vezes o orçamento previsto. Apesar do alto orçamento requisitado em um curto período de tempo, o programa não afetou negativamente o investimento em bolsas no exterior para áreas não contempladas pelo programa, causando, na verdade, um “efeito CsF” de aumento do número de bolsas para todas as grandes áreas do conhecimento. Outra constatação refere-se à manutenção da complementaridade da formação de recursos humanos tanto no Brasil quanto no exterior durante o período de implementação do programa. O consenso é que o investimento em formação de recursos humanos em todas as áreas do conhecimento é vital para o desenvolvimento científico e tecnológico do país e, neste sentido, o CsF foi um estímulo; todavia, a qualidade do gasto público, sobretudo com as bolsas da graduação, é questionada por especialistas de C\&T e requer investigações

Em adição, na pós-graduação, é mister discutir, em profundidade, o balanceamento dos investimentos em mobilidade acadêmica internacional e em fomento à pesquisa, sendo esta uma crítica ao Ciência sem Fronteiras, que utilizou recursos do Fundo Nacional de Desenvolvimento Científico e Tecnológico (FNDCT) contra a vontade de uma parcela - considerável - da comunidade científica nacional, pois o FNDCT foi originalmente desenhado para fomento à pesquisa e não para formação de recursos humanos. Foi uma alternativa de financiamento do CsF que gerou desequilíbrios no funcionamento do Sistema Nacional de CT\&I.

Revista Brasileira de Políticas Públicas e Internacionais, v.2, n.2, Dezembro/2017, pp. 52-82. 
MANÇOS, Guilherme de Rosso e COELHO, Fernando de Souza. Internacionalização da Ciência Brasileira: subsídios para avaliação do programa Ciência sem Fronteiras

\subsection{Colaboração científica internacional}

Glänzel e Schubert (2004) demonstram que, década a década, há uma tendência de crescimento quanto ao número de países que participam de uma mesma publicação em coautoria, com base na origem das instituições participantes. Em 1990, mais de 93\% das publicações em coautoria envolviam apenas dois países, ou seja, menos de 7\% das publicações em coautoria internacional tinham a participação de 3 ou mais países. Já em 2000, o percentual de publicações com 3 ou mais países atinge $17 \%$.

Países europeus, além de Estados Unidos, Japão e Austrália, apresentaram nas últimas quatro décadas um crescimento contínuo na razão entre publicações internacionais e o total de publicações - tendência que acelera a partir 2001 -, diferente dos países dos BRICS que não demonstram um padrão de continuidade e parecem seguir uma outra lógica. No Reino Unido, por exemplo, de acordo com as publicações indexadas pela base de dados Web of Science e coletadas via plataforma InCites ${ }^{\mathrm{TM}}$, 26,44\% do total de publicações eram em coautoria internacional no ano de 2001, subindo para 47,83\% em 2015 (Thomsom Reuters, 2016).

Dentre as publicações científicas realizadas por pesquisadores com afiliação institucional no Brasil em 1980, 17,61\% possuíam pelo menos um coautor com afiliação internacional. Essa porcentagem é flutuante ao longo dos anos, porém observa-se uma tendência de crescimento brusco em dois momentos: em meados da década de 1980 até meados da década de 1990 e entre o período de 2010 e 2015, como mostrado na curva vermelha da Figura 7. Em ambos os períodos o número de bolsas de pós-graduação e pós-doutorado no exterior implementadas pelo CNPq também aumentou (curva azul). No intervalo entre 1995 e 2010, a porcentagem de colaboração científica do Brasil decresce lentamente, assemelhando-se ao comportamento de histerese em que um sistema tende a conservar as suas propriedades logo após o estímulo que as gerou (Mayergoyz, 2003).

Os dados apresentados na Figura 7 têm coeficiente de correlação $\rho=0,96$ se considerado o decênio 1986-1995 e $\rho=0$,89 entre 2010-2015, valores de correlação considerados muito forte e forte, respectivamente. Uma plausível explicação sobre o comportamento dessas flutuações é,

Revista Brasileira de Políticas Públicas e Internacionais, v.2, n.2, Dezembro/2017, pp. 52-82. 
MANÇOS, Guilherme de Rosso e COELHO, Fernando de Souza. Internacionalização da Ciência Brasileira: subsídios para avaliação do programa Ciência sem Fronteiras

portanto, que o aumento da quantidade de bolsistas brasileiros de pós-graduação no exterior em um determinado período temporal tenha influência direta no aumento da colaboração científica do Brasil com outros países naquele mesmo período. Neste caso, é razoável esperar que as colaborações científicas que surgiram tentem se manter conectadas mesmo que haja descontinuidade de bolsas logo em seguida.

Figura 7 - Evolução de bolsas de pós-graduação no exterior pelo CNPq e a porcentagem das publicações científicas do Brasil com coautoria internacional (1980-2015)

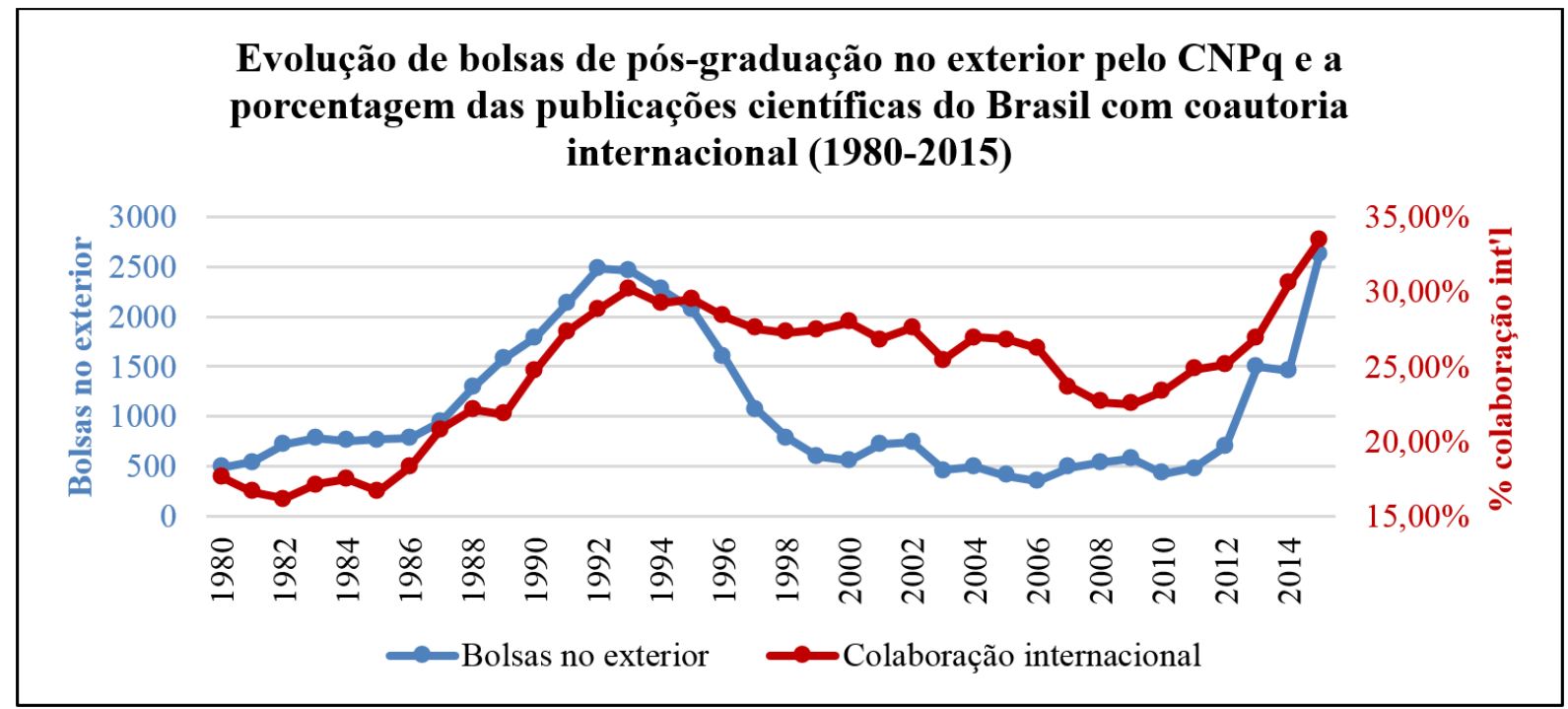

Fonte: Elaborado pelos autores com dados do CNPq (bolsas no exterior) e da base Web of Science/Thomsom Reuters (\% colaboração internacional).

Apesar de tais correlações apresentarem indícios de que a mobilidade acadêmica internacional fomenta a colaboração científica, apenas com este simples teste estatístico não é possível generalizar a hipótese. O sistema de educação superior brasileiro utiliza apenas a língua portuguesa em quase toda a sua totalidade e recebe - relativamente - poucos pesquisadores estrangeiros. Neste sentido, enviar pesquisadores ao exterior se mostra um mecanismo em potencial para o Brasil, mas podem haver estratégias melhores para países com sistemas diferentes.

Revista Brasileira de Políticas Públicas e Internacionais, v.2, n.2, Dezembro/2017, pp. 52-82. 
MANÇOS, Guilherme de Rosso e COELHO, Fernando de Souza. Internacionalização da Ciência Brasileira: subsídios para avaliação do programa Ciência sem Fronteiras

É possível argumentar, portanto, que há indícios de que as bolsas do Ciência sem Fronteiras entre 2012 e 2015 foram um estímulo para aumentar a colaboração científica internacional do Brasil no mesmo período. Além disso, considerando um padrão observado anteriormente, pode-se hipotetizar que os pesquisadores brasileiros tentarão manter as suas colaborações individuais e influenciarão no nível de colaboração internacional alcançado pelo país após o estímulo feito pelas bolsas de mobilidade acadêmica internacional. Por isso, o decrescimento da curva vermelha deve ser amenizado mesmo com a interrupção do programa. Vale ressaltar que a CAPES também financia milhares de bolsas exterior para pós-graduandos e esse fator também deve ser considerado. Porém, a análise de padrões anteriores por parte dos investimentos da CAPES fica impedida haja vista que os dados da plataforma GEOCAPES estão disponíveis apenas a partir do ano de 1998.

De maneira simples, também é possível analisar as caraterísticas dos países quanto à quantidade de publicações científicas e quanto à qualidade destas publicações. Ao analisarmos os 20 países que mais receberam bolsistas do Ciência sem Fronteiras, vemos que eles se destacam entre os países com maior competitividade em termos de quantidade e qualidade de publicações científicas. O montante de bolsistas recebidos por estes 20 países corresponde a 98,93\% do total de bolsas implementadas.

Entende-se, grosso modo, que o programa Ciência sem Fronteiras cumpriu com o objetivo de enviar alunos de graduação e pós-graduação para realizarem estágio no exterior com a finalidade de manter contato com sistemas educacionais competitivos em relação à pesquisa, tecnologia e inovação. Entretanto, mesmo em países com sistemas de CT\&I desenvolvidos e maduros, a experiência individual de cada bolsista é peculiar a cada um e pode ser influenciada positiva ou negativamente de acordo com a universidade de destino, com os interesses profissionais e acadêmicos do estudante/pesquisador, com a maturidade e experiências anteriores, com a habilidade de se adaptar a novos ambientes e a existência de instrumentos de monitoramento (ou mecanismos de controle) dos bolsistas enquanto estavam no exterior - seja pela CAPES e CNPq, seja pela universidade de origem. Neste sentido, uma análise da relação dos bolsistas com as instituições de destino e suas respectivas experiências individuais se faz necessário, a partir de pesquisas que se

Revista Brasileira de Políticas Públicas e Internacionais, v.2, n.2, Dezembro/2017, pp. 52-82. 
MANÇOS, Guilherme de Rosso e COELHO, Fernando de Souza. Internacionalização da Ciência Brasileira: subsídios para avaliação do programa Ciência sem Fronteiras

utilizem de survey e grupos focais. Outrossim, vale investigações no âmbito das próprias instituições de educação superior que participaram do CsF, baseada em entrevistas em profundidade com os alunos (e egressos) envolvidos - tal como o estudo de Pinto (2017) no IFPB.

\subsubsection{Mobilidade acadêmica e coautoria internacional: uma proposta}

A exploração científica das relações no nível de instituições e de pesquisadores pode ser uma potencial alternativa para verificar se a mobilidade acadêmica internacional é um bom mecanismo de incentivo à colaboração científica, pois dessa maneira é possível realizar análises com grupos de controle. Um exemplo deste tipo de colaboração no nível de pesquisadores é apresentado com o caso do pesquisador Eduardo Ferracioli-Oda (EFO), estudante de medicina da Universidade de São Paulo e ex-bolsista do Ciência sem Fronteiras na Yale University, Estados Unidos. Em 2013, EFO publicou um artigo em coautoria internacional (\#) com o pesquisador Michael H. Bloch (MHB) da Yale University e outros dois autores, fruto das pesquisas geradas enquanto bolsista nos Estados Unidos (Ferracionali-Oda et al., 2013). Ao buscar o currículo Lattes de EFO, há a informação sobre outro artigo científico com coautorias internacionais publicado em 2015 com outros 6 autores (\#\#), incluindo MHB (Coughlin et al., 2015). A Figura 8 apresenta um grafo das conexões de EFO em coautoria internacional com os oitos pesquisadores com quem publicou artigos científicos. Em azul estão os autores do artigo \# e as suas conexões; em amarelo estão os autores do artigo \#\# e as suas conexões; em verde estão EFO e MHB, coautores de ambos os artigos.

Revista Brasileira de Políticas Públicas e Internacionais, v.2, n.2, Dezembro/2017, pp. 52-82. 
MANÇOS, Guilherme de Rosso e COELHO, Fernando de Souza. Internacionalização da Ciência Brasileira: subsídios para avaliação do programa Ciência sem Fronteiras

Figura 8 - Grafo de coautorias dos artigos \# de 2013 e \#\# de 2015, sendo (a) conexões entre todos os autores e (b) conexões apenas de EFO
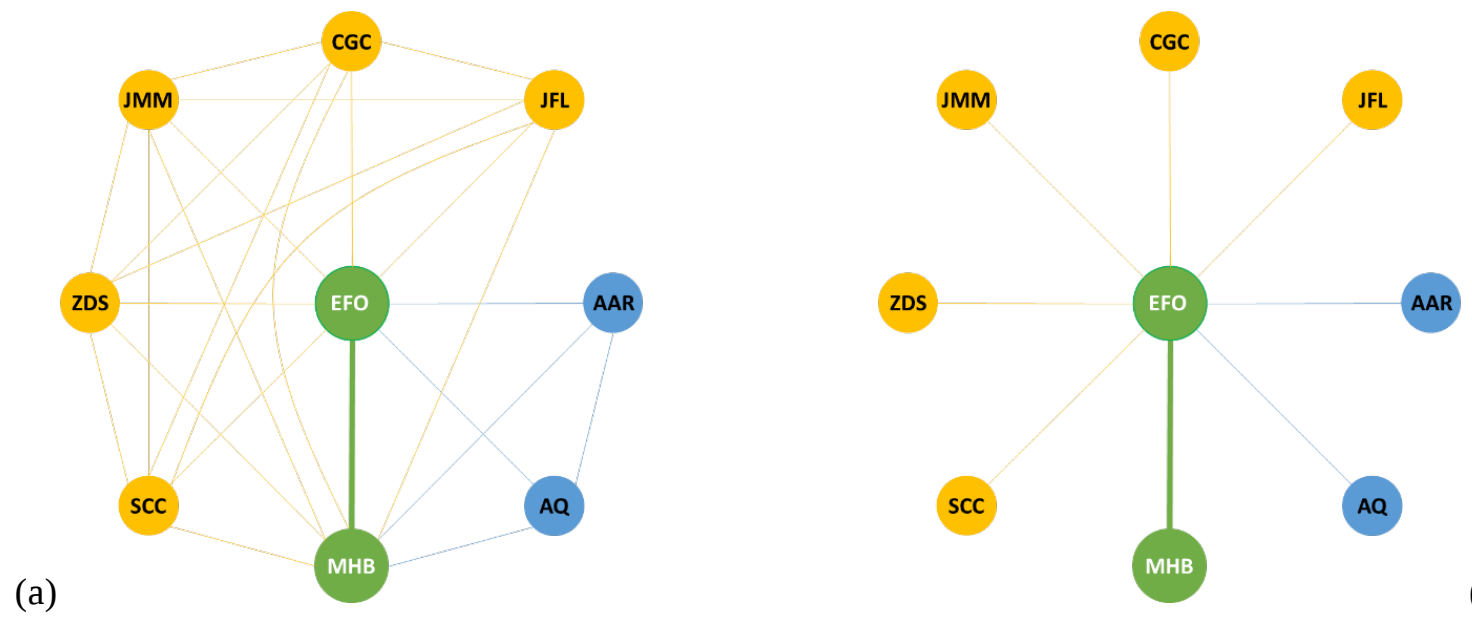

(b)

Fonte: Elaborado pelos autores.

Ainda que pontual, este é um claro exemplo de como experiência de mobilidade acadêmica internacional gerou produção científica a partir de colaboração científica internacional. Em complemento, infere-se também que a interação entre os pesquisadores continuou mesmo após o retorno do bolsista EFO ao Brasil, vide artigo publicado em 2015. Portanto, além dos indícios que o investimento em mobilidade acadêmica internacional pode ser um mecanismo de incentivo à colaboração científica internacional, pode-se observar que o vínculo uma vez criado tende a permanecer ativo.

O Lattes de EFO não o identifica como bolsista do Ciência sem Fronteiras, o que dificulta a coleta de dados extensiva para o caso de outros pesquisadores. Uma proposta de avaliação é que seja confeccionado um mapeamento das publicações de todos os bolsistas do CsF e a análise de coautorias dessas publicações, em comparação com um grupo controle de pesquisadores que não realizaram mobilidade acadêmica internacional. Outro caminho possível, é analisar as relações de coautoria do Brasil específicas com os países que mais receberam bolsistas do Ciência sem

Revista Brasileira de Políticas Públicas e Internacionais, v.2, n.2, Dezembro/2017, pp. 52-82. 
MANÇOS, Guilherme de Rosso e COELHO, Fernando de Souza. Internacionalização da Ciência Brasileira: subsídios para avaliação do programa Ciência sem Fronteiras

Fronteiras. Essas são algumas pistas metodológicas para um processo avaliativo dos resultados (e impactos) do CsF que considere a dimensão produção de conhecimento e colaboração científica internacional.

\section{Considerações finais}

Apesar dos esforços investidos ao longo das últimas décadas, o Brasil ainda tem um longo caminho a trilhar no campo de CT\&I. Visando maior competitividade e inserção da ciência brasileira nas redes internacionais de $P \& D$, estratégias de internacionalização vêm sendo formuladas e implementadas pelos órgãos que compõem o Sistema Nacional de CT\&I. Dentre o rol de ações - projetos e atividades - governamentais neste processo, encontram-se os programas de mobilidade acadêmica internacional, como o programa Ciência sem Fronteiras, que concedeu mais de 100.000 bolsas para estudantes e pesquisadores brasileiros e estrangeiros realizarem intercâmbio no exterior. Este programa de internacionalização e formação de recursos humanos, considerado uma iniciativa audaciosa no contexto de políticas públicas de internacionalização e de ciência, tecnologia e inovação, dispendeu mais de R \$10 bilhões dos cofres públicos e articulou interesses de todo o SNCTI.

Diante dessa magnitude, se faz importante avaliar seus resultados, cujas recentes análises abarcam a gestão do programa, relações internacionais, os impactos na formação e currículo, e interesses em línguas estrangeiras. No entanto, deve-se considerar também o interesse em conhecer os impactos do Ciência sem Fronteiras na colaboração científica internacional e na produção de conhecimento, fato que tornam relevantes as primeiras análises que envolvem essas perspectivas e que tem uma grande audiência da mídia, das agências de fomento e dos especialistas em C\&T, ainda mais com a decisão de descontinuidade de parcela do programa no período recente.

Sobre o panorama que precedeu a formulação do programa Ciência sem Fronteiras, o o artigo joga luz em problemas fundamentais do campo de CT\&I no país, quais sejam: (i) o déficit na formação de recursos humanos nas áreas de ciências básicas, engenharias e demais áreas tecnológicas; e (ii) a baixa inserção científica do Brasil no cenário internacional. Diante destes

Revista Brasileira de Políticas Públicas e Internacionais, v.2, n.2, Dezembro/2017, pp. 52-82. 
MANÇOS, Guilherme de Rosso e COELHO, Fernando de Souza. Internacionalização da Ciência Brasileira: subsídios para avaliação do programa Ciência sem Fronteiras

problemas, o CsF surge como um programa de empoderamento - politicamente - pela presidente Dilma Roussef e insere-se como um das alternativas de política pública alinhadas à estratégia desenvolvida pelo MCTI: a Estratégia Nacional de Ciência, Tecnologia e Inovação 2012-2015.

Com sua rápida criação e implementação a partir de 2011, em 2015 o programa conseguiu atingir a meta de conceder 101.000 bolsas de intercâmbio acadêmico distribuídas em sete diferentes modalidades e que levaram os beneficiários para vivenciarem os sistemas acadêmicos e educacionais em quase cinquenta países - dentre os quais estão aqueles mais competitivos na conjuntura global. Entretanto, o custo previsto de R\$3 bilhões para implementação foi extrapolado em mais de três vezes, gerando dúvidas sobre a qualidade do gasto público (eficiência do processo) e críticas quanto à eficácia do programa, bem como ao deslocamento de recursos orçamentários de fomento à pesquisa do FNDCT para o CsF.

Outros pontos críticos apontados por especialistas e ecoados pela opinião pública dizem respeito ao grande foco em bolsas de graduação e quanto ao critério de escolha das áreas prioritárias, bem como o exagero do simbolismo político ao estipular uma meta de concessão de 100.000 bolsas em um período de quatro anos. Por outro lado, dados analisados neste artigo indicam que, no que pese a alocação de recursos financeiros pelo programa em bolsas no exterior para grandes áreas como engenharia e ciências exatas e da terra, o CsF teve um efeito positivo para o aumento da oferta de bolsas no exterior em todas as áreas, inclusive as não contempladas pelo programa como ciências humanas e linguística, letras e artes. O CsF também não retirou recursos financeiros das bolsas de formação de recursos humanos no país. Para lastrear tais análises em dados mais amplos e sólidos, recomenda-se que as informações sobre a implementação do programa presentes no Painel de Controle do Ciência sem Fronteiras e na ferramenta Bolsistas pelo Mundo tenham liberadas as permissões para download ou exportação em .xls (ou qualquer formato de planilha), assim como é o Sistema de Informações Georreferenciadas da CAPES (GeoCAPES) e a seção de Séries Históricas do CNPq.

Resultados da pesquisa da qual derivou este artigo mostraram que há indícios para corroborar a hipótese de que o investimento em mobilidade acadêmica internacional pode ser um mecanismo eficaz para estimular e manter a colaboração científica a nível internacional. A fim de

Revista Brasileira de Políticas Públicas e Internacionais, v.2, n.2, Dezembro/2017, pp. 52-82. 
MANÇOS, Guilherme de Rosso e COELHO, Fernando de Souza. Internacionalização da Ciência Brasileira: subsídios para avaliação do programa Ciência sem Fronteiras

viabilizar e automatizar a coleta extensiva de dados bibliométricos de publicações dos pesquisadores brasileiros, recomenda-se que o currículo Lattes permita ao pesquisador que tenha usufruído de alguma bolsa em sua formação indicar também, além da agência de fomento financiadora, a opção de registro do programa a que foi vinculado.

Apesar de indícios benéficos, devido à implementação recente deste programa, é fato que ainda não se tem de forma sistêmica uma noção clara e precisa dos resultados e impactos. E, caso haja resultados concretos já no curto prazo, ainda não há estudos que demonstrem se são significativos ou não. Talvez seja necessário aguardar mais alguns anos ou décadas para uma análise aprofundada sobre os impactos e efeitos do Ciência sem Fronteiras na produção e na colaboração científica. Afinal, os macro resultados dos investimentos em CT\&I são, invariavelmente, de médio ou longo prazo.

Com o alcance da cifra de mais de 100.000 bolsas concedidas, de fato espera-se que com o passar dos anos mudanças ocorram nas redes de coautorias no sentido de criar mais e melhores conexões científicas e tecnológicas entre o Brasil - e seus pesquisadores - e os países estrangeiros que receberam participantes do Ciência sem Fronteiras, indicando que as redes de cooperação estão crescendo e se tornando mais complexas. Considerando tal expectativa, uma evolução natural de pesquisas, portanto, será em vistas de realizar mais e melhores avaliações sobre o impacto do programa nas mais diversas áreas científicas e nas respectivas redes de coautorias.

Ainda quanto ao Ciência sem Fronteiras, menciona-se a avaliação do Senado Federal (2015, p. 61) que afirma que o programa "foi capaz de aumentar a visibilidade internacional da educação superior brasileira (...) [e] lançou bases mais firmes para a inserção das universidades e outras instituições brasileiras em programas de cooperação internacional no campo da pesquisa”. Esta avaliação foi realizada no pleito de 2015 por iniciativa da Comissão de Ciência, Tecnologia, Inovação, Comunicação e Informática (CCT) e contou com a participação de ex-bolsistas do programa, gestores das agências de fomento CAPES e CNPq, professores e reitores das universidades, gestores de relações internacionais, técnicos em políticas de CT\&I e membros da comunidade científica. As conclusões do Poder Legislativo estão demonstradas em um relatório que contempla 17 recomendações, incluindo a continuidade do Ciência sem Fronteiras como Revista Brasileira de Políticas Públicas e Internacionais, v.2, n.2, Dezembro/2017, pp. 52-82. 
MANÇOS, Guilherme de Rosso e COELHO, Fernando de Souza. Internacionalização da Ciência Brasileira: subsídios para avaliação do programa Ciência sem Fronteiras

recomendação primeira. Esta avaliação oficial, e suas recomendações, podem (e devem) ser discutidas para que sejam corroboradas ou contrapostas; daí a importância de processos de avaliação de políticas públicas e programas governamentais complementares, realizados por acadêmicos e instituições independentes.

Por fim, considerando que: (i) as soluções para resolver o problema de formação de recursos humanos qualificados para CT\&I e de inserção científica e tecnológica do Brasil no cenário internacional são de longo prazo; (ii) o objetivo de promover a consolidação, expansão e internacionalização da ciência e tecnologia, da inovação e da competitividade brasileira por meio do intercâmbio e da mobilidade internacional ainda é estratégico para o país; (iii) adquiriu-se muitos aprendizados no decorrer da implementação do programa CsF; e (iv) há avaliações que fornecem subsídios para melhorias, sugere-se que o governo federal deve envidar esforços para manter uma política pública de mobilidade acadêmica internacional como Ciência sem Fronteiras, mesmo que em dimensões menores e de maneira reformulada - ao contrário da tomada de decisão simplista de extinção e/ou congelamento parcial ou total do programa sem o amparo (ou confronto) de evidências dos seus resultados.

\section{Referências}

Altbach, P. G., \& Knight, J. (2007). The Internationalization of Higher Education: Motivations and Realities. Journal of Studies in International Education, v. 11, n. 3-4, p. 290-305.

Almeida, P. H. (2017). O compartilhamento do conhecimento entre pesquisadores nacionais e internacionais do Programa Ciência sem Fronteiras. Curitiba: Universidade Federal do Paraná.

Archanjo, R. (2015). Globalização e Multilingualismo no Brasil Competência Linguística e o Programa Ciência Sem Fronteiras. Revista Brasileira de Linguística Aplicada, v. 15, n. 3, p. 621656.

Archanjo, R. (2016). Saberes sem Fronteiras: Políticas para as migrações Pós-modernas. DELTA: Documentação de Estudos em Lingüística Teórica e Aplicada, v. 32, n. 2, p. 515-541.

Aveiro, T. M. M. (2014). O programa Ciência sem Fronteiras como ferramenta de acesso à mobilidade internacional. Tear: Revista de Educação, Ciência e Tecnologia, v. 3, n. 2.

Bernal, J. D. (1939). The Social Function of Science. London: George Routledge \& Sons Ltd.

Revista Brasileira de Políticas Públicas e Internacionais, v.2, n.2, Dezembro/2017, pp. 52-82. 
MANÇOS, Guilherme de Rosso e COELHO, Fernando de Souza. Internacionalização da Ciência Brasileira: subsídios para avaliação do programa Ciência sem Fronteiras

Bido, M. C. F. (2015). Will science without borders program bring relevant changes for brazilian curriculum? ECCS, p. 382-393.

Borges, R. A.; \& Garcia-Filice, R. C. (2016). A língua inglesa no Programa Ciência sem Fronteiras : paradoxos na política de internacionalização. Interfaces Brasil/Canadá, v. 16, n. 1, p. 72-101.

Brasil (2010). Ministério Da Educação. Censo da Educação Superior. Brasília: MEC.

Brasil (2012). Ministério Da Ciência Tecnologia e Inovação. Estratégia Nacional de Ciência, Tecnologia e Inovação 2012 - 2015. Brasília: MCTI.

Brasil (2016). Painel de Controle do Programa Ciência sem Fronteiras. Disponível em: $<$ www.cienciasemfronteiras.gov.br/web/csf/painel-de-controle>.

Senado Federal do Brasil. (2015). Relatório de avaliação do programa ciência sem fronteiras.

Castro, C. M. et al. (2012). Cem mil bolsistas no exterior. Interesse nacional, p. 25-36.

Chaves, G. M. N. (2015). As bolsas de graduação-sanduíche do programa Ciência sem Fronteiras: uma análise de suas implicações educacionais. Brasília: Universidade Católica de Brasília.

Conceição, O. C.; \& França, M. T. A. (2016). O Programa Ciência Sem Fronteiras Contribui Na Formação Dos Estudantes? Uma Análise a Partir Do Enade 2013. p. 1-19.

Coughlin, C. G. et al. (2015). Meta-Analysis: Reduced Risk of Anxiety with Psychostimulant Treatment in Children with Attention-Deficit/Hyperactivity Disorder. Journal of Child and Adolescent Psychopharmacology, v. 25, n. 8, p. 611-617.

Decreto $n^{0}$ 7.642, de 13 de dezembro de 2011. Institui o Programa Ciência sem Fronteiras. Recuperado de http://www.planalto.gov.br/ccivil_03/_ato2011-2014/2011/decreto/d7642.htm.

Dorigon, T. (2015). O Programa Idiomas sem Fronteiras Analisado a partir do Ciclo de Políticas. Brazilian English Language Teaching Journal. December, pp. 4-20.

Dutra, R. C. De A.; \& Azevedo, L. F. (2016). Programa “Ciência sem Fronteiras”: geopolítica do conhecimento e o projetos de desenvolvimento brasileiro. Ciência Sociais Unisinos, v. 52, n. 2, p. 234-243.

Ferracioli-Oda, E. et al. (2013). Meta-Analysis: Melatonin for the Treatment of Primary Sleep Disorders. PloS ONE, v. 8, n. 5, p. 6-11.

Gardner, E. (2011). Brazil promises 75,000 scholarships in science and technology. Nature.

Gil, A. C. (1987). Como Elaborar Projetos de Pesquisa. 4. ed. São Paulo: Atlas.

Glänzel, W., \& Schubert, A. (2004). Analysing Scientific Networks through Co-Authorship. Dordrecht: Springer Netherlands. p. 257-276.

Grieco, J. A. (2015). Fostering Cross-Border Learning and Engagement Through Study Abroad

Revista Brasileira de Políticas Públicas e Internacionais, v.2, n.2, Dezembro/2017, pp. 52-82. 
MANÇOS, Guilherme de Rosso e COELHO, Fernando de Souza. Internacionalização da Ciência Brasileira: subsídios para avaliação do programa Ciência sem Fronteiras

Scholarships: Lessons From Brazil’S Science Without Borders Program. University of Toronto.

Guimarães-Iosif, R. (2016). Programa Ciência sem Fronteiras: a tradução da política de internacionalização brasileira no Canadá. Canoas: Interface Brazil/Canadá, p. 16-39.

Jibeen, T.; \& Khan, M. A. (2015). Internationalization of Higher Education : Potential Benefits and Costs. v. 4, n. 4, p. 196-199.

Knight, J. (1994). Internationalization: Elements and Checkpoints. Ottawa: Canadian Bureau for International Education.

Leydesdorff, L. et al. (2013). International Collaboration in Science: The Global Map and the Network. El Profesional de la Información.

Lucchesi, M. A. S., \& Malanga, E. B. (2014). A Internacionalização da Educação Superior: uma análise do programa Ciência sem Fronteiras no Brasil, caminhos e desafios. Revista Internacional de Ciencias Sociales Interdisciplinares, v. 3, n. 1, p. 87-101.

Martins, A.; \& Reis, E. C. (2015). Internacionalização na UFSC: Análise do Programa Inglês Sem Fronteiras e do Curso Extracurricular de Inglês. Mar del Plata: XV Colóquio Internacional de Gestão Universitária (CIGU).

Mayergoyz, I. D. (2003). Mathematical Models of Hysteresis and their Applications. 2nd. ed. Nova York: Academic Press.

Mcmanus, C.; \& Nobre, C. A. (2017). Brazilian Scientific Mobility Programa - Science without Borders - Preliminary Results and Perspectives. Anais da Academia Brasileira de Ciências, v. 89, n. 1, p. 773-786.

Oliveira, E. M. (2015). Problemas nas “fronteiras” - um caso para ensino sobre o programa Ciência sem Fronteiras. Rio de Janeiro: Fundação Getúlio Vargas.

Oliveira, J. S. (2015). A Internacionalização da Educação Superior nas Relações Internacionais do Brasil: O Caso do Programa Ciência sem Fronteiras. Brasília: Universidade de Brasília.

Oliveira, L. C. (2016). Saberes com Fronteiras: elucidando alguns aspectos do programa Ciência sem Fronteiras nas Licenciaturas em Ciências Exatas e da Terra da Região Sudeste. Caraguatatuba: Instituto Federal de Educação, Ciência e Tecnologia de São Paulo.

Pinto, P. N. C. (2017). Internacionalização da Educação Superior: um estudo sobre o Programa Ciência sem Fronteiras no IFPB. Dissertação de Mestrado Profissional do Programa de PósGraduação em Políticas Públicas, Gestão e Avaliação da Educação Superior. João Pessoa: Universidade Federal da Paraíba.

Rede CsF. (2015). Universidade Presente - um guia para acompanhar o aluno no exterior. Belo Horizonte: Rede CsF.

Santos, F. (2014). CAPES e CNPq apresentam avaliação preliminar do Ciência sem Fronteiras. Disponível em: <http://www.cienciasemfronteiras.gov.br/web/csf/views/-

Revista Brasileira de Políticas Públicas e Internacionais, v.2, n.2, Dezembro/2017, pp. 52-82. 
MANÇOS, Guilherme de Rosso e COELHO, Fernando de Souza. Internacionalização da Ciência Brasileira: subsídios para avaliação do programa Ciência sem Fronteiras

/journal_content/56_INSTANCE_VF2v/214072/5100172>.

Santos, F. M. T. (2014). Teacher training in Brazil: the challenges of international partnerships. Revista Brasileira de Pós-Graduação, v. 11, n. 26, p. 1001-1025, 2014.

Scopus (2017). H Index - Country Ranking. Scimago Lab. Disponível em: <http://www.scimagojr.com/countryrank.php>.

Secchi, L. (2016). Análise de Políticas Públicas: diagnóstico de problemas, recomendações de soluções. São Paulo: Ed. Cengage Learning.

Shannon, T. A, Jr. (2012). Avanço Estratégico do Brasil. Americas Quaterly.

Soares, M. S. (2014). As contradições do ensino de língua estrangeira no brasil reveladas pelo programa Ciência sem Fronteiras. Universidade Estadual de Maringá, Maringá.

Terziev, V.; \& Georgiev, M. (2017). Importance of human resources to social development. Paris: Proceedings of Academics World $57^{\text {th }}$ Conference.

Thiengo, L. C.; \& Mari, C. L. (2014). O Ciência sem Fronteiras: sobre o lugar e a função do conhecimento no ensino superior brasileiro. Germinal: Marxismo e Educação em Debate, v. 6, n. 1, p. 122-133.

Thomsom Reuters. (2017). InCitesTM. Disponível em: <incites.thomsonreuters.com>.

Wit, H. D. (1998). Changing rationales for the internationalization of higher education. International Higher Education, v. 15, n. 3, p. 2-3.

World Bank. 2016. World Development Indicators: Science and Technology. Disponível em: $<$ http://wdi.worldbank.org/table/5.13\#>.

World Intellectual Property Organization (WIPO). (2017). Statistical Country Profiles. Intellectual Property Statistics. Disponível em: <http://www.wipo.int/ipstats/en/statistics/country_profile/>.

Revista Brasileira de Políticas Públicas e Internacionais, v.2, n.2, Dezembro/2017, pp. 52-82. 